\section{El Programa Bienal de Arte Joven}

\author{
Stella Scarciófolo \\ scarciofolostella@gmail.com \\ Matías Bonfiglio \\ matiasbonfiglio86@gmail.com
}

Cultura(s) en clave de extensión universitaria / Apuestas

\author{
María Cecilia Farías \\ mceciliafarias@gmail.com \\ Secretaría de Extensión Social y Cultural. \\ Universidad Nacional del Litoral, Argentina.
}

\title{
Presentación
}

La Bienal de Arte Joven de la Universidad Nacional del Litoral (UNL) es una plataforma de formación, difusión y exhibición, donde los jóvenes de la ciudad y la región se presentan, representan y reflejan. El arte, la experiencia cultural y educativa y la creación artística se vinculan directamente con la Universidad para producir nuevos sentidos y significados.

La primera Bienal nació hace 25 años a partir de una propuesta de la Federación Universitaria del Litoral (FUL) y la UNL. Desde aquel entonces reúne voces, visiones y expresiones de los noveles creadores emergentes de la ciudad y la región con el fin de convertir sus producciones y propuestas en bienes públicos y sociales.

En el año 2018, en el marco de las celebraciones de los 100 años de la Reforma Universitaria y en vísperas del centenario de la UNL, el eslogan que se propuso para la $13^{\text {a }}$ edición fue "Florecer de entusiasmo, crear en libertad" y estuvo inspirado en un verso de un poema del estudiante reformista del Litoral Pablo Vrillaud: "Reencontrarse en un ideal, abstraerse en un pensamiento, darse entero a un ensueño, empenacharse de lirismo, florecer de entusiasmo, eso es vivir".

\section{Bienal de Arte Joven 2018 "Florecer de entusiasmo, crear en libertad"}

En esta edición de la Bienal nos surgió la necesidad de relacionarnos con nuevos públicos y actores sociales con un doble propósito: por un lado, recomponer relaciones existentes y, por otro, fundar nuevos vínculos para facilitar la promoción y la socialización del arte joven. Decidimos reformular "la Bienal" pensando fundamentalmente en clave territorial ampliada, entendiendo al territorio como espacio integrado de manera inescindible a la sociedad y la cultura que esta produce, buscando poner al alcance de todos los públicos las poéticas de los emergentes artísticos. En consecuencia, la Dirección de Extensión Cultural facilitó un modo de socializar las experiencias creativas y artísticas en un ámbito de diálogo cómplice entre pares y con el público, a la vez que reivindicó el rol de la Universidad en torno al debate de las nuevas corrientes estéticas y el estado del arte actual en la región. En esta edición buscamos ser receptivos con las nuevas propuestas, tendencias y prácticas de la cultura. Con el avance de la tecnología digital en el marco del proceso de globalización, se resignifican las percepciones que se tenían del mundo. Las viejas estructuras y las maneras tradicionales de "ver" se desvanecen. La cultura y las artes en general no son ajenas a estos procesos y quedan caducas las antiguas estructuras y clasificaciones. Las nociones de campos, estilos, técnicas y procedimientos no son exhaustivas, ya que incluyen aquellos productos que no caben dentro de las viejas clasificaciones. En búsqueda de apertura e inclusión, ponderamos la versatilidad del arte que se aggiorna, donde los bordes de se 
diluyen, se solapan, se fusionan y se integran valorando su capacidad para producir nuevos significados y representaciones acordes a estos tiempos. En este marco es que se propone el nuevo concepto de Bienal con el imperativo de resignificar la relación entre cultura, arte, sociedad y educación, trabajando sobre los siguientes objetivos:

- Instalar a la Bienal de Arte Joven de la UNL en la comunidad de Santa Fe y la región como un evento de encuentro y disfrute del arte.

- Convocar a la juventud de la región a compartir sus creaciones en un espacio abierto e inclusivo de la diversidad.

- Concebir ambientes propicios para dar lugar a la innovación y el conocimiento de la cultura y sus múltiples dimensiones con plena participación de estudiantes en todo el proceso.

- Fortalecer las relaciones y generar nuevos vínculos con las instituciones educativas de todos los niveles de Santa Fe y del sitio.

- Distinguir y diferenciar las producciones del entretenimiento de las elaboraciones de la cultura.

- Poner en valor la cultura como cualificadora de desarrollo social.

- Vincular y garantizar la participación de todos los actores sociales.

- Reformular el alcance de La Bienal hasta el nivel nacional al incluir en la convocatoria a los países que integran la red de universidades públicas de Asociación de Universidades Grupo Montevideo: Argentina, Bolivia, Brasil, Chile, Paraguay y Uruguay.

\section{Camino a la Bienal: workshop "pensar la Bienal"}

Previamente a la edición de la Bienal, la primera línea de acción fue llevar a cabo un workshop destinado a diseñadores, artistas, estudiantes y público en general, con el fin de construir la identidad visual de este encuentro. Consistió en dos jornadas intensivas en las que participaron más de 170 estudiantes universitarios y secundarios. El workshop estuvo coordinado por distintos profesores de la Facultad de Arquitectura, Diseño y Urbanismo, y artistas plásticos santafesinos invitados para la ocasión.

\section{Espacio de clínicas}

Se trató de espacios gratuitos para la formación de jóvenes artistas con la guía de especialistas de reconocido prestigio, de modo de acercar la reflexión teórica a la práctica artística, para alentar y acompañar a los artistas en sus propias búsquedas. Funcionó como una plataforma complementaria teórica y conceptual para el desarrollo de proyectos artísticos de cara a la $13^{\circ}$ Bienal de Arte Joven al integrar la educación y la cultura como instrumentos complementarios a los modelos educativos vigentes. A partir de distintas instancias (artesanías, artes plásticas, escénicas, multimedia, música, transmedia, etc.), se pretendió integrar (desde la escuela de enseñanza media hasta la universidad), necesidades vitales y hábitos culturales de la comunidad y la región. Se fomentó el deseo de aprender, la autorreflexión y el debate para estimular el pensamiento crítico desde la perspectiva renovada de las artes.

Algunas de las clínicas desarrolladas fueron: "Interactividad, forma, sonido y silencio. Proyectos tridimensionales interactivos", a cargo del profesor Fabricio Fernandino; "Bases 
de la ilustración experimental. Técnicas gráficas en el dibujo creativo", a cargo de Rodrigo Ciccarelli; "Esto no es un retrato. Clínica de instalaciones artísticas colectivas", a cargo de Ávalos, Bertola y Otero; "Series web para redes sociales. De la idea a la producción", con Carlos Essmann, entre otras que integraron una agenda intensiva de 15 instancias formativas llevadas a cabo en el trayecto de seis meses y en las que participaron más de 500 jóvenes y adolescentes.

\section{Mediación cultural como puente}

Con el propósito de sociabilizar, acercar, invitar y sumar participaciones al encuentro artístico, se convocó a estudiantes de la UNL a formar parte voluntariamente como mediadores culturales. Se conformaron equipos nómades que tuvieron la función de presentar la Bienal en las distintas escuelas secundarias de la ciudad e invitar a los estudiantes mayores de 13 años a sumar sus producciones artísticas en la instancia de concurso que propone la Bienal. Los mediadores realizaron intervenciones en los diferentes espacios públicos y escuelas visitadas para promocionar el evento y generar producciones colectivas que luego estuvieron expuestas en el encuentro. Además, en una segunda instancia participaron en las actividades culturales y educativas que integraron el programa de la Bienal.

A los fines de cumplir con el objetivo de inclusión, expansión y sociabilización, los mediadores culturales visitaron las distintas Escuelas de Trabajo situadas en barrios vulnerables de la ciudad de Santa Fe, un polo de atracción clave, para que sus participantes conozcan y participen de la Bienal.

\section{Talleres culturales en las Escuelas de Trabajo}

Las Escuelas de Trabajo son espacios de referencia social distribuidos estratégicamente en distintos sectores no céntricos de la ciudad, dependientes del gobierno de la ciudad de Santa Fe. Pensando de manera descentralizada, creamos una oferta de siete talleres culturales (cerámica artística y utilitaria, photosmart, serigrafía, encuadernación artesanal, maquillaje artístico y estampados textiles) que tuvieron una duración de 8 meses. Cada uno de ellos se desarrolló en tres etapas: 1) Experimentá: guiados por los distintos docentes, esta etapa se orientó específicamente a la presentación y aproximación a los materiales y técnicas. 2) Creá: instancia que propuso iniciar un recorrido de búsqueda creativa y personal tomando como base e instrumento la técnica. 3) Emprendé: los asistentes, acompañados individualmente por los docentes y otros emprendedores, analizaron el modo en el que la oferta del taller pudiera ser insumo para un potencial emprendimiento independiente y sostenible en el tiempo. Esta etapa exige una continuidad y compromiso temporal, por lo que aun se está llevando a cabo.

Para la elaboración de las propuestas y para su realización se trabajó de manera integrada con los equipos del Área de Territorio Cultural y del Área de Territorio y Políticas Públicas de la Secretaría de Extensión Social y Cultural de la UNL. 


\section{Feria de Emprendedores}

La $13^{\mathrm{a}}$ Bienal de Arte Joven propuso un espacio para que los jóvenes emprendedores independientes de la ciudad y la región dieran a conocer sus producciones. Se llevó a cabo una convocatoria donde se invitó a aquellos jóvenes emprendedores que tuvieran en funcionamiento un microemprendimiento propio a exhibir y comercializar sus productos, impulsando el desarrollo de aquellas iniciativas comerciales y laborales que tuvieran como base la cultu$\mathrm{ra}$, el diseño y la innovación. A la convocatoria se postularon 52 emprendimientos locales, de los cuales fueron seleccionados 20 para participar en la Bienal. El espíritu de la iniciativa fue mostrar la diversidad de elaboraciones que existen en el ecosistema cultural y productivo de la región. Se recibieron todas aquellas propuestas que estuvieran relacionadas con: elaboración de indumentaria, estampados textiles, accesorios, diseño de joyas, carteras, bolsos, mochilas, cartucheras, billeteras, elementos decorativos intervenidos, juguetes artesanales, reciclados varios, cuadernos, libretas, agendas, calendarios, gráfica adhesiva, imanes, postales, lápices, señaladores, arte objetos, lámparas, muebles, etcétera.

\section{Ambiente cultural}

Esta fue una actividad conjunta con la Secretaría de Ambiente y Espacios Públicos del gobierno de la ciudad de Santa Fe. Consistió en la elaboración de grandes esculturas colectivas realizadas a partir del "superciclaje" de materiales inorgánicos de residuo y descarte. Se trabajó de manera intensiva en tres jornadas completas y esta actividad abordó cuatro dimensiones:

- Dimensión estética: la obra se degrada y se transforma con el transcurso del tiempo y la participación de las personas. Objet trouvé: sacar de contexto materiales de uso convencional y darle carácter de arte por voluntad del artista y los actores.

- Dimensión semántica: reivindicar la tectónica y la capacidad que tiene la materia para contar historias.

- Dimensión arquitectónica y urbana: recuperación de espacios degradados con mínimas intervenciones. Transitoriamente, los espacios se activan con el arte y la apropiación humana. Transformación de espacios vacantes en espacios de representación social en uso.

- Dimensión pedagógica: generar conciencia sobre el reciclaje y reutilización de materiales.

Docentes a cargo: Dr. Fabrício Fernandino, de la Universidad Federal de Minas Gerais, y el Prof. Abel Monasterolo, de la Escuela Provincial de Artes Visuales Juan Mantovani y director del Museo Municipal de Artes.

\section{Jurado de selección}

Lo que respecta a la instancia de jura y curaduría fue un punto de inflexión dentro del proyecto de la Bienal de Arte Joven. Esto se debió a que dicho proceso (selección, curaduría y premiación) fue llevado a cabo por un equipo integrado por 15 personalidades de destacada trayectoria nacional e internacional provenientes de diversas áreas del arte y la cultura. Por un lado, la implementación de la jura se realizó de manera transversal y se discutió interdisciplinariamente la valoración de todas las presentaciones. Se trabajó exclusivamente con el material digital descargado de las fichas individuales de inscripción aplicando el mismo cri- 
terio de selección a la totalidad de los proyectos inscriptos, considerando fundamentalmente la diferencia de categorías (categoría $\mathrm{A}$, de 13 a 18 años; y categoría $\mathrm{B}$, de 18 a 35 años). Por otra parte, el proceso curatorial se efectuó en dos etapas. La primera de ellas se realizó en el mismo contexto que el de los jurados y se pudo participar y aportar en la toma de decisiones. En esta instancia, se organizó conceptualmente el material seleccionado por el equipo de jurados. La totalidad de las obras seleccionadas se organizó en campos temáticos o conceptuales, teniendo el equipo de curadores libertad plena para nombrarlos y definirlos. Como condición, el equipo de jurados y curadores debió dejar por escrito los lineamientos conceptuales que enlazaron las obras en estos agrupamientos por conceptos. A los fines de agudizar y profundizar la lectura sobre los trabajos expuestos para la premiación, se realizó una segunda etapa del proceso curatorial in situ. En esta oportunidad, el equipo se redujo, pero se intentó mantener la heterogeneidad. En esta segunda instancia se produjo la toma de decisiones finales luego de ver y ubicar las obras en su contexto real de exposición.

\section{El evento}

La Bienal tuvo lugar en las instalaciones de la antigua estación de Ferrocarriles Manuel Belgrano, uno de los edificios más emblemáticos de la ciudad. Los espacios se colmaron con exposiciones, producciones, recitales y actividades culturales de diversa índole. Esta edición contempló propuestas para todas las edades, de 13 a 35 años, motivo por el cual se previó un horario extendido con propuestas permanentes de talleres no formales para niños, adolescentes y visitantes, garantizando, de este modo, la participación y acceso a las escuelas. Las visitas fueron recibidas por los mediadores culturales, quienes los guiaron a través de juegos y recorridos interpretativos. Asimismo, en concordancia con nuestro compromiso educativo como universidad, se ofreció una propuesta de 10 espacios de formación a través de clínicas, talleres y seminarios a cargo de reconocidos artistas y docentes de la región, quienes abordaron un amplio espectro de temas vinculados a distintas áreas de la cultura y el arte (percusión corporal, cine para adolescentes, cosplay, ilustración, creación de cuentos, curaduría, entre otros). En el evento también participaron, con distintas propuestas, algunos espacios institucionales de la Universidad y otros invitados, además de los 20 emprendimientos jóvenes seleccionados. A lo largo de cinco días se pudo visitar una presentación y exhibición permanente de más de 200 proyectos y obras que quedaron seleccionados para esta edición. Una posibilidad única para conocer las inquietudes y el trabajo de los jóvenes artistas emergentes de la ciudad y la región.

\section{Reflexión final}

Planificamos este proyecto como un espacio inclusivo, no solo porque fue generado por la Universidad (que tiene a la gratuidad entre sus principios) sino también porque la Bienal representó y representa un espacio de libre acceso que fomenta la participación de toda la comunidad (artistas y público) como un vector garante de la construcción de ciudadanía.

Creemos que toda política pública cultural que se considere integral debe incorporar la voz de la comunidad, dotándola de posibilidades para ejercer su derecho a la participación en las prácticas culturales. 
Persiguiendo el objetivo de concretar el espacio de la Bienal como un "territorio para la utopía", donde las producciones artísticas puedan constituirse en bienes públicos y sociales, sostenemos que las bienales se orientan a partir de un ideario institucional que reúne a organizadores, jurados, curadores, educadores y públicos diversos. Esta gran exhibición se destacó por la convocatoria a jurados y curadores con formaciones diferentes $\mathrm{y}$, por consiguiente, con diferentes puntos de vista. En síntesis, esta edición histórica se propuso "repensar la Bienal" en sus dimensiones temporales y espaciales, tomando como premisa los valores que dirigieron el sentido y la conciencia de aquellos hombres que sostuvieron el ideario reformista de 1918 para poder, desde el hoy, adaptarlo a las demandas culturales y sociales de la actualidad, crear respuestas acordes a los tiempos que corren, y asumir el compromiso de trabajar en pos de una democracia cultural que garantice para todos libertad para crear e igualdad de oportunidades. 